\title{
Flame Aerosol Synthesis of Freestanding ZnO Nanorods
}

\author{
Vishwanath Gandikota ${ }^{1}$, Yangchuan Xing ${ }^{1,2}$ \\ ${ }^{1}$ Department of Materials Science and Engineering, Missouri University of Science and Technology, Rolla, USA \\ ${ }^{2}$ Department of Chemical Engineering, University of Missouri, Columbia, USA \\ Email:xingy@missouri.edu
}

Received November 24, 2013; revised December 30, 2013; accepted January 12, 2014

Copyright (C 2014 Vishwanath Gandikota, Yangchuan Xing. This is an open access article distributed under the Creative Commons Attribution License, which permits unrestricted use, distribution, and reproduction in any medium, provided the original work is properly cited. In accordance of the Creative Commons Attribution License all Copyrights (C) 2014 are reserved for SCIRP and the owner of the intellectual property Vishwanath Gandikota, Yangchuan Xing. All Copyright (C) 2014 are guarded by law and by SCIRP as a guardian.

\section{ABSTRACT}

ZnO can be made into many nanostructures that have unique properties for advanced applications, such as piezoelectric and pyroelectric materials. ZnOnanorod is one of the nanostructures that possess advanced properties. This paper reports a gas phase flame process to continuously synthesize aerosols of ZnOnanorods in large quantities. Unlike previous work, our process shows that pure ZnOnanorods can be made in a freestanding form rather than growing on a substrate surface. It was found that the ZnOnanorods preferentially grow in the thermodynamically stable direction [001] in the gas phase with different aspect ratios, depending on flame process conditions. The ZnOnanorod aerosols are highly crystalline and have a hexagonal geometry. Raman and photoluminescence spectroscopic studies showed that there are no structural defects in the nanorods, which have energy band gap of $3.27 \mathrm{eV}$ in the near $\mathrm{UV}$ region. It was demonstrated that the gas phase flame reactor can provide a convenient means for continuous production of highly pure aerosols of ZnOnanorods.

\section{KEYWORDS}

\section{ZnO Aerosols; Freestanding Nanorods; Flame Synthesis; Flame Reactor; Continuous Synthesis}

\section{Introduction}

$\mathrm{ZnO}$ is an II-VI semiconductor with a large band gap (3.37 eV) that can be excited by using short wavelength emissions such as UV radiation at room temperature. It has a Wurtzite structure and belongs to the non-centrosymmetric point group of $6 \mathrm{~mm}$ [1]. This property makes $\mathrm{ZnO}$ a highly suitable material for piezoelectric and pyroelectric applications. Due to its high photon emission efficiency, $\mathrm{ZnO}$ can be considered as a substitute material for $\mathrm{TiO}_{2}$ used in many photocatalytic applications [2,3]. It has also been demonstrated to be a promising photoanode material in dye-sensitized solar cells [4]. By the addition of suitable dopants, its band gap can be changed and hence its photonic properties can be altered [5,6]. In addition, $\mathrm{ZnO}$ and its composites have been used for gas sensing applications [7]. Based on the applications for which it is being used, $\mathrm{ZnO}$ can be made into various nanostrucutures such as nanoparticles, nanorods, nanobelts, nanocombs and nanocages [1].

However, synthesis of highly pure ZnOnanorods has not been very successful in a continuous process. They have been studied in various processes such as flame spray pyrolysis (FSP), laser ablation plume, metalorganic vapor phase epitaxy (MOVPE), chemical vapor deposition (CVD), and surface growth in a counterflow diffusion flame (CDF) [8-12]. ZnO has been also made by using a thermal plasma technique with or without substrates $[13,14]$. Except the FSP and plasma technique, all others were surface techniques, meaning that the $\mathrm{ZnO}$ nanorods were grown on a support surface, making mass production of the material difficult.

The FSP technique is a continuous process, but it can only produce a small percentage of rod shaped $\mathrm{ZnO}$. Initial efforts were done by Akhtar et al. [15] and Tani et al. [16], but it was found that the formation process of the product cannot be controlled. To rectify this drawback, Height et al. [8] added dopants like In and Sn to promote the growth of ZnOnanorods in a specific direction. Although the addition of dopants increased formation of the nanorods, it still cannot achieve all rod structures. In ad- 
dition, the dopants introduced impurities into the $\mathrm{ZnO}$ nanorods. Peng et al. [14] synthesized ZnOnanorods in a continuous process without support substrates by using a radio frequency thermal plasma system. They used $\mathrm{Zn}$ metal powders as the precursor. The metal was evaporated in the hot plasmas and condensed into $\mathrm{ZnO}$. The plasma technique involves evaporation of the metal first and is an energy intensive process.

Previously, Xu et al. [12,17] used a CDF reactor to synthesize $1 \mathrm{D}$ nanostructures of $\mathrm{ZnO}$ and $\mathrm{WO}_{2}$. In both cases, a metal-coated substrate was used for preferential growth of 1D nanostructure with other chemical precursors. The technique is a non-continuous surface technique, and the use of a substrate limits its production capacity of the ZnOnanorods [14]. In a similar process, Rao and Zheng produced iron and copper oxide nanostructures in a flat flame by oxidizing a metal surface [18]. Most recently, iron oxide nanorods and $\mathrm{MoO}_{2}$ nanowires were grown in CDF flames by Merchan-Merchan et al. $[19,20]$ by inserting their respective metal plates into the flames. Nanowires grow on the cold plates in a CVD process, but they must be placed at a precise location for the desired 1D nanostructure growth morphology [12, 19].

In this paper, we report a study using a CDF reactor to produce pure $\mathrm{ZnO}$ aerosols in the shape of nanorods. Unlike the previous work, this work is a continuous, substrate-free aerosol process, and is scalable to mass production. It is shown that the CDF reactor can be used to produce high crystalline ZnOnanorods in freestanding form. It is also shown that, by varying the different process parameters, the size of nanorod aerosols can be controlled to certain degree.

\section{Experimental Methods}

\subsection{Flame Reactor and Nanorod Synthesis}

This work employed a rectangular CDF reactor, first developed by Chung and Katz [21] to study the nucleation of refractory compounds, and later redesigned by Xing et al. [22,23] to produce nanoparticles of different morphologies. An illustration of the CDF reactor is shown in Figure 1. The CDF reactor consists of two vertical channels of rectangular cross sections that are positioned opposite to each other. The rectangular channels (100 $\mathrm{mm} \times 10 \mathrm{~mm}$ ) have a high aspect ratio (10:1), which makes the dimension of one of the sides negligible in the morphology evolution of nanoparticles [23]. Hydrogen diluted with nitrogen in one channel and oxygen diluted with nitrogen in the other are introduced into the reactor at specific flow rates. A uniform and flat flame is formed in between the channels. Adjusting the flow rates of the gases can control the flame location. The flame established produces a temperature gradient between the

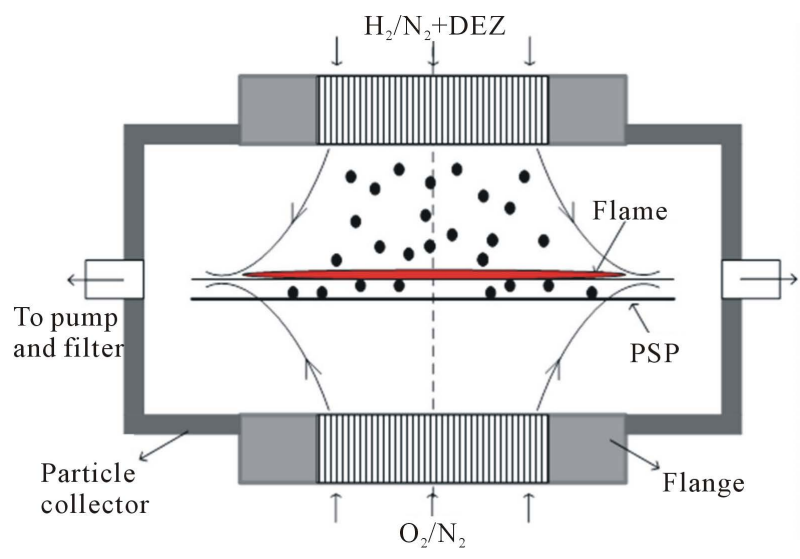

Figure 1. Sectional illustration of the CDF reactor and the particle collector, showing gas flow streamlines and the particle flow configuration. Aerosols produced are ejected at the particle stagnation plane (PSP). The produced aerosols are pumped out with the gases after combustion, and are collected on a filter installed downstream.

channels. Particle morphology can be controlled using the CDF reactor because of the different chemical environment present on either side of the flame [23]. In this experiment, the Zn precursor was introduced to the hydrogen side (see Figure 1).

To synthesize ZnOnanorods, diethyl zinc (DEZ, Sigma Aldrich) was used as the chemical precursor. DEZ is a highly volatile and flammable liquid. In use, DEZ was diluted with hexane in a glove box in the ratio of 1:1 for easy handling. The solution is then filled in a gastight syringe and introduced into the reactor using a syringe pump. This setup helps in adjusting the precursor flow rate with precision. The combustion gases are hydrogen (UHP grade, Airgas) and oxygen (HP grade, Airgas), both diluted with nitrogen (UHP grade, Airgas).

To study the effects of various process parameters, three types of experiments were performed: 1) Effect of gas flow rate; 2) Effect of precursor flow rate; 3) Effect of dilution. For each experiment, we conducted two runs. To evaluate the effect of a particular process parameter on ZnOnanorod growth, experiments were designed in such a fashion that the other parameters were kept constant. For example, to study gas flow rate, the dilution and the concentration of the precursor, i.e., the ratio of the precursor flow rate to the combustion gas flow rate was kept constant. Similarly, to study the precursor flow rate the concentration of the precursor was varied at constant gas flow rates and dilution. The dilution studies were done at two flow rates of $\mathrm{N}_{2}$ (in $\mathrm{H}_{2}$ stream or in $\mathrm{O}_{2}$ stream) dilution. The experimental conditions used to produce $\mathrm{ZnO}$ are shown in Table 1.

The $\mathrm{Zn}$ precursor fed to the $\mathrm{H}_{2}$ stream and carried into the reactor and react to form the $\mathrm{ZnO}$ aerosols. The aerosols produced were collected on a filter paper in a self-made nanoparticle collector (see Figure 1). The col- 
Table 1. Process parameters used for synthesis of ZnOnanorods. The gas flow rates are in $\mathrm{L} / \mathrm{min}$ and the precursor (DEZ) flow rate in $\mathrm{mL} / \mathrm{hr}$.

\begin{tabular}{ccccccccccc}
\hline & \multicolumn{1}{c}{ Condition A } & \multicolumn{1}{c}{ Condition B } \\
\cline { 2 - 11 }${ }^{*}$ & $\mathrm{H}_{2}$ & $\mathrm{~N}_{2}$ & $\mathrm{~N}_{2}$ & $\mathrm{O}$ & $\mathrm{O}$ & $\mathrm{N}$ & $\mathrm{N}_{2}$ & $\mathrm{~N}_{2}$ & $\mathrm{O}_{2}$ & $\mathrm{DEZ}$ \\
& & $\left(\mathrm{H}_{2}\right)$ & $\left(\mathrm{O}_{2}\right)$ & & & & $\left(\mathrm{H}_{2}\right)$ & $\left(\mathrm{O}_{2}\right)$ & & \\
\hline 1 & $\mathbf{1 . 0}$ & 1.5 & 0.5 & 1.0 & 2.0 & $\mathbf{2 . 5}$ & 3.75 & 1.0 & 2.0 & 5.0 \\
2 & 2.0 & 3.0 & 1.0 & 2.0 & $\mathbf{4 . 0}$ & 2.0 & 3.0 & 1.0 & 2.0 & $\mathbf{6 . 0}$ \\
3 & 2.0 & $\mathbf{3 . 0}$ & 1.0 & 2.0 & 4.0 & 2.0 & $\mathbf{4 . 0}$ & 1.0 & 2.0 & 4.0 \\
\hline
\end{tabular}

lector was installed on the sides of the CDF reactor and the combustion gases were pulled through a downstream filter using a vacuum pump. Filter paper membranes (Nylon, Millipore) of $47 \mathrm{~mm}$ in diameter were used. The porous membranes have $400 \mathrm{~nm}$ pores on average. The collection line was heated to $c a .90^{\circ} \mathrm{C}$ to avoid any water condensation in the copper line. The filter paper is enough for collection of $200 \mathrm{mg}$ powder at each time in the small-scale experiments. For large-scale production, larger filters or filter bags can be used, which can be arranged in series so that the continuous production is not interrupted. The thermophoretic sampling technique as reported previously [22] has also been used to collect the particles near the flame directly.

\subsection{Nanorod Characterizations}

$\mathrm{X}$-ray diffraction (XRD) studies on the collected powders were carried out on a Philips X'Pert X-ray diffractometer with a $2 \theta$ angle varying from $6^{\circ}$ to $90^{\circ}$ at a scan rate of $0.025 \mathrm{deg} / \mathrm{s}$, using a $\mathrm{Cu} \mathrm{K}-\alpha$ radiation. The operating conditions for the diffractometer are $45 \mathrm{kV}$ and $40 \mathrm{~mA}$. A Tecnai F20 transmission electron microscope (TEM) was used to characterize the morphology and structures of the nanorods. TEM images obtained were analyzed using Image J (NIST), Digital micrograph (Gatan), and TEM image analysis (TIA). Fast Fourier Transform (FFT) in the digital micrograph and TIA software was used to obtain the selected area electron diffraction (SAED) patterns. Crystal maker software was used to simulate the SAED patterns. Quantitative calculations have been done on the SAED pattern to determine the orientation of the nanorods. These calculations were then compared to the simulated results for accuracy.

\section{Results and Discussion}

\subsection{Nanorod Morphology and Crystalline Phase}

Figure 2(a) shows a low magnification TEM image of the $\mathrm{ZnO}$ aerosols produced. It can be clearly seen that the aerosol powder produced has rod like nanostructures. Despite variations in aspect ratios, the aerosols can be characterized as ZnOnanorods. The $\mathrm{ZnO}$ powder from the collector was characterized by XRD to deter-

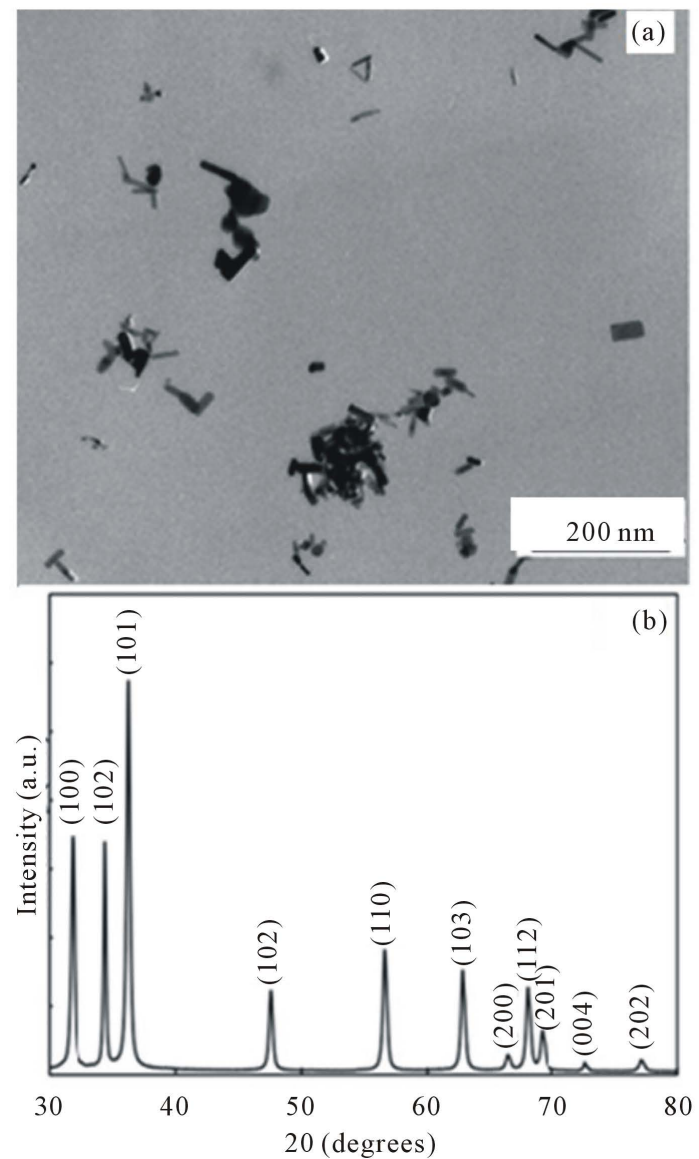

Figure 2. (a) Low magnification TEM image of the collected ZnO aerosols showing rod like nanostructures. (b) XRD pattern of the highly crystalline ZnOnanorod without any impurities.

mine their crystallinity and crystal planes. The results are shown in Figure 2(b). The peaks obtained in the XRD pattern are well indexed to the hexagonal wurtzite structure of $\mathrm{ZnO}$, with lattice constants of $a=$ $0.3249 \mathrm{~nm}$ and $c=0.5207 \mathrm{~nm}$ [1]. The sharp peaks in the XRD pattern show that the $\mathrm{ZnO}$ powder obtained is highly crystalline. No peaks due to undecomposed Zn precursor or carbon (from hexane) are seen, indicating that the $\mathrm{ZnO}$ powder obtained is highly pure. As discussed earlier, $\mathrm{ZnO}$ finds various applications in the semiconductor industry where purity is an important requirement [24]. The flame process to make them in pure substance without adding a promoter or catalyst is advantageous.

\subsection{Effect of Gas Flow Rates}

It can be seen from Figure 1 that there is a layer that forms below the flame and is known as the particle stagnation plane (PSP). This PSP is formed due to the thermophoretic effects of the particles. Generally in a CDF process the precursor reacts above the flame and forms 
nuclei, which grow into aerosol particles. Particles exits out before they reach the PSP [22]. In other words, the distance between the flame and PSP may determine the size of the nanoparticles formed in this flame. The average velocity or momentum of the gas and its dilution rate can be calculated by using the gas flow rate and the area of the channel exit. The momentum ratio (on one side, say $\mathrm{H}_{2}$ side) is the sum of the gas momentum on the hydrogen side to the sum of the gas momentum on the oxygen side. The higher the momentum ratio is, the shorter the distance between the flame and PSP, which in turn leads to shorter residence time for the particles to evolve in the flame [23]. Calculating the momentum ratios for Condition A and Condition B assuming a constant channel exit, we can clearly see that momentum ratio is higher in the case of $\mathrm{B}$ than $\mathrm{A}$, in the experimental run conditions listed in Table 1.

Figures 3(a) and (b) show two typical TEM images of the ZnOnanorods synthesized in A-1 (i.e., condition A run 1 ) and $B-1$, respectively. In these two experiments, the $\mathrm{Zn}$ precursor concentrations were kept the same, but changes were on their momenta. The momentum ratio $(\varepsilon)$ is the momentum flow rate $(\dot{P})$ of gases in the $\mathrm{H}_{2}$ stream to that in the $\mathrm{O}_{2}$ stream:

$$
\varepsilon=\dot{P}_{\mathrm{H}_{2}} / \dot{P}_{\mathrm{O}_{2}} .
$$

where

$$
\begin{aligned}
& \dot{P}=\dot{m} v, \\
& \dot{m}=p q .
\end{aligned}
$$

and

$$
v=q / S
$$

with $q$ being the volumetric flow rate, $v$ the average velocity, $\dot{m}$ the mass flow rate, and $S$ the slot channel cross-section area.

The momentum ratio calculations for A- 1 and $\mathrm{B}-1$ are shown in Table 2. The momentum ratio is 1.59 in A-1 and that in B-1 is 2.49. The images clearly show that nanorods synthesized in B-1 are shorter than the nanorods synthesized in A- 1 . This is attributed to that the higher momentum ratio in B-1 results in a shorter residence time for the nanorods to grow. Hence, it can be said that higher gas flow rates result in shorter ZnOnanorods under the given precursor feeding rate.

\subsection{Effect of Precursor Flow Rates}

This effect has been studied by varying the precursor flow rate and keeping the gas flow rates and dilution constant. As discussed earlier in the paper, precursor concentration, which is the ratio of the precursor flow rate to that of the combustible gas, is higher in the case of B-2 compared to condition A-2. Figure 4(a) corresponds to condition A-2 and Figure 4(b) corresponds to the condi-

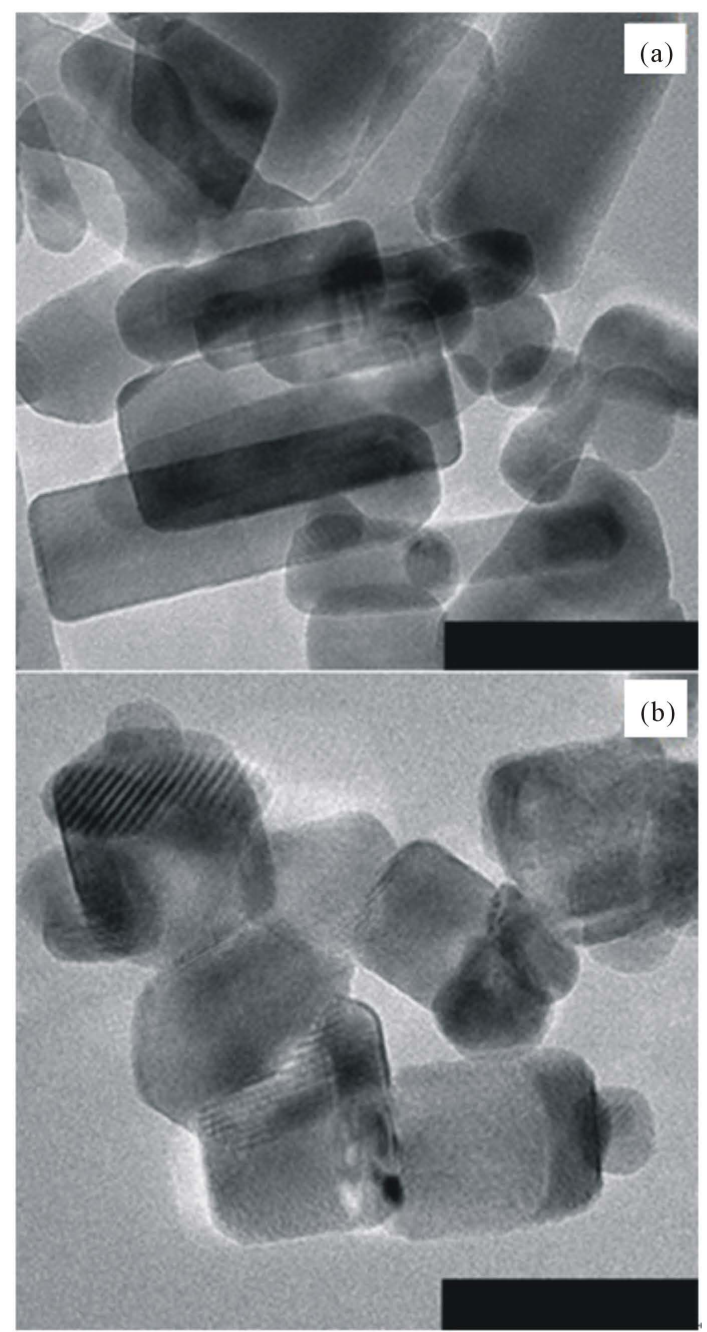

Figure 3. (a) ZnOnanorods synthesized at a lower gas flow rate (Condition A-1). (b) ZnOnanorods synthesized at higher gas flow rates (Condition B-1). Note that the precursor feeding concentration is the same for both experiments. Scale bar $=100 \mathrm{~nm}$.

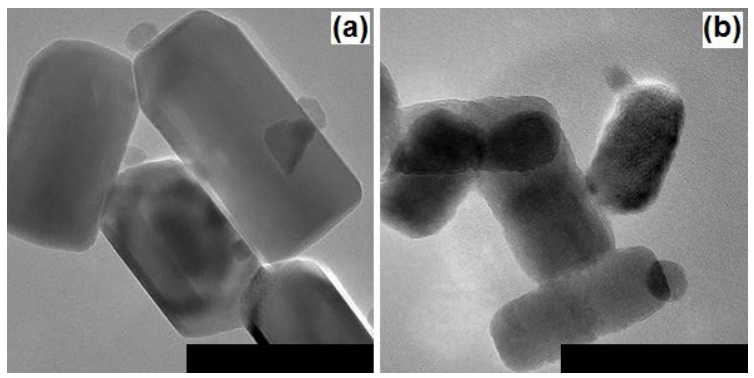

Figure 4. (a) ZnOnanorods synthesized at lower precursor flow rates (Condition A-2). (b) ZnOnanorods synthesized at higher precursor flow rates (Conditon B-2). Scale bar $=100$ nm.

tion B-2, respectively. Images shown in Figures 4(a) and (b) demonstrate that, in case of higher precursor concentration, much shorter nanorods were formed as com- 
Table 2. Average velocity, molar flow rate, average momentum calculations for conditions A-1 and B-1*

\begin{tabular}{|c|c|c|c|c|c|c|}
\hline & Gases & Volumetric flow rate (L/min) & Mass flow rate (kg/s) & Average Velocity $(\mathrm{m} / \mathrm{s})$ & Momentum flow rate $\left(\mathrm{kg} \cdot \mathrm{m} / \mathrm{s}^{2}\right)$ & Momentum ratio \\
\hline \multirow{2}{*}{ A-1 } & $\mathrm{H}_{2}+\mathrm{N}_{2}$ & 2.50 & $3.28 \mathrm{E}-05$ & 4.17E-02 & $1.36 \mathrm{E}-06$ & \multirow{2}{*}{1.59} \\
\hline & $\mathrm{O}_{2}+\mathrm{N}_{2}$ & 1.50 & $3.42 \mathrm{E}-05$ & $2.50 \mathrm{E}-02$ & $8.56 \mathrm{E}-07$ & \\
\hline \multirow{2}{*}{ B-1 } & $\mathrm{H}_{2}+\mathrm{N}_{2}$ & 6.25 & $8.19 \mathrm{E}-05$ & $1.04 \mathrm{E}-01$ & $8.53 \mathrm{E}-06$ & \multirow{2}{*}{2.49} \\
\hline & $\mathrm{O}_{2}+\mathrm{N}_{2}$ & 3.00 & $6.85 \mathrm{E}-05$ & $5.00 \mathrm{E}-02$ & $3.42 \mathrm{E}-06$ & \\
\hline
\end{tabular}

pared to the lower concentration case. This can be attributed to the fact that the number of $\mathrm{ZnO}$ nuclei forming in the case of condition $\mathrm{B}$ is much higher than that of condition $\mathrm{A}$, and hence, the resulted morphology is observed.

While nucleation of such metal oxides in a gas phase should be very fast, their stable nuclei for growth are dependent on the concentration of the precursor $[22,25]$ and some could become stagnant [26]. When the characteristic time for reaction is fast, growth by collisions dominates the process [22]. What was evidenced is that the morphology of condition of B (Figure 4(b)) showed rough surface of the rods, whereas at low precursor concentration, crystal with defined surfaces were obtained. This observation can be also attributed to the outburst of aerosol formation in the higher concentration case, in which the primary particles aggregate but without enough time to recrystallize in the preferred growth direction. Such aerosols, although have a rod-like shape, would not be stable, and they would recrystallize if given enough time, which is still under study for aerosol nanorod stability in our lab.

\subsection{Effect of Gas Dilution}

The amount of dilution in the combustion gas determines the peak flame temperature [27]. Also, a higher dilution rate implies that the momentum ratio is higher in the case of B compared to A. Hence, we expect to see smaller particles at higher dilutions (lower temperatures). Figures 4(a) and 5 show the nanorods synthesized at dilution rates of $1.5\left(q_{\mathrm{N}_{2}\left(\mathrm{H}_{2}\right)} / q_{\mathrm{H}_{2}}\right)$ and 2.0, respectively. It can be clearly seen that much shorter nanorods with aspect ratios close to unity are formed at higher gas dilution rates, as expected. They are more like regular aerosols from a gas phase, showing partially round particles. The shorter nanorods seen in this case could be a result of the dual effect of peak flame temperature and higher gas momentum ratio. The probable mechanism for the growth of the ZnOnanorods will be further discussed below. However, an in-depth analysis and the exact growth mechanism have to be known to comprehend the effect of these parameters individually.

\subsection{Growth Mechanism of ZnOnanorods}

The TEM grids obtained from thermophoretic sampling were used to study the growth mechanism of the

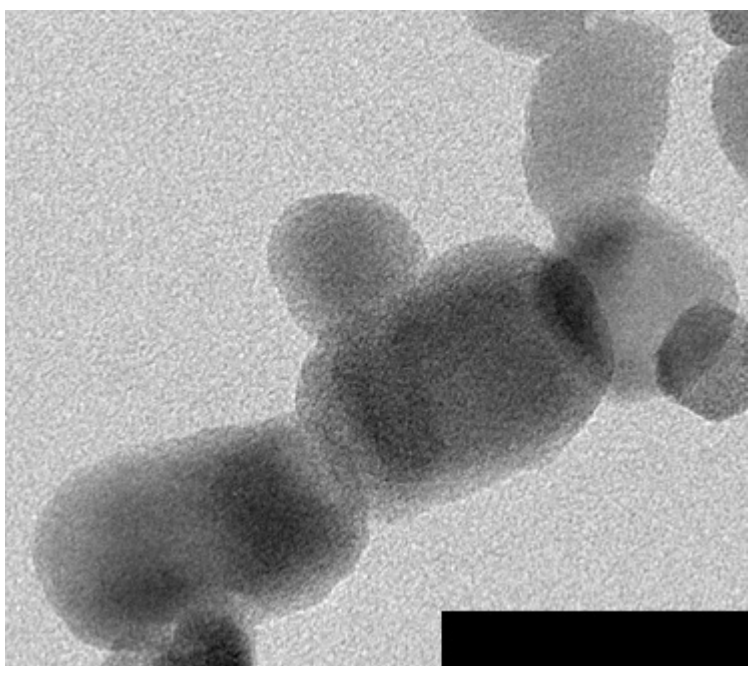

Figure 5. ZnOnanorods synthesized at a higher dilution rate in Condition B-3 than A-3 (same as A-2). Scale bar = $50 \mathrm{~nm}$.

ZnOnanorods. A high-resolution TEM image shown in Figure 6(a) proves our previous conclusion that the ZnOnanorods produced are highly crystalline. These nanorods were produced under run A-1 condition for the precursor flow rate and dilution studies. Calculations have been made using Image J, and it was found that the ZnOnanorods are approximately $10 \mathrm{~nm}$ in diameter. The FFT of the electron diffraction is shown in the inset of Figure 6(a). The circular spot on (002) indicates that the nanorod growth is parallel with it in plane direction [28]. Also, it can be seen that there is indeed a (001) spot on the SAED pattern, which is absent in the case of a HCP crystal. The presence of (001) spot indicates that the nanorod obtained is really small and hence they are not enough planes that can destructively interfere with the diffracted waves from the (001) plane. This observation is consistent with previous studies that have shown the [001] direction is the preferential growth direction $[1,13$, 29]. The [001] direction is also the most thermodynamically stable direction for growth of ZnOnanords [1]. The relative growth rates for ZnOnanorods along different directions have been reported [28].

A head-on image taken from a ZnOnanorod standing inclined on the TEM grid support is shown in Figure 6(b), with its electron diffraction pattern in the inset. We can clearly see that the base of the nanorod is a typical hexagon with a width of $19 \mathrm{~nm}$ and a $120^{\circ}$ angle. From the diffraction pattern and the image, it can be inferred that 

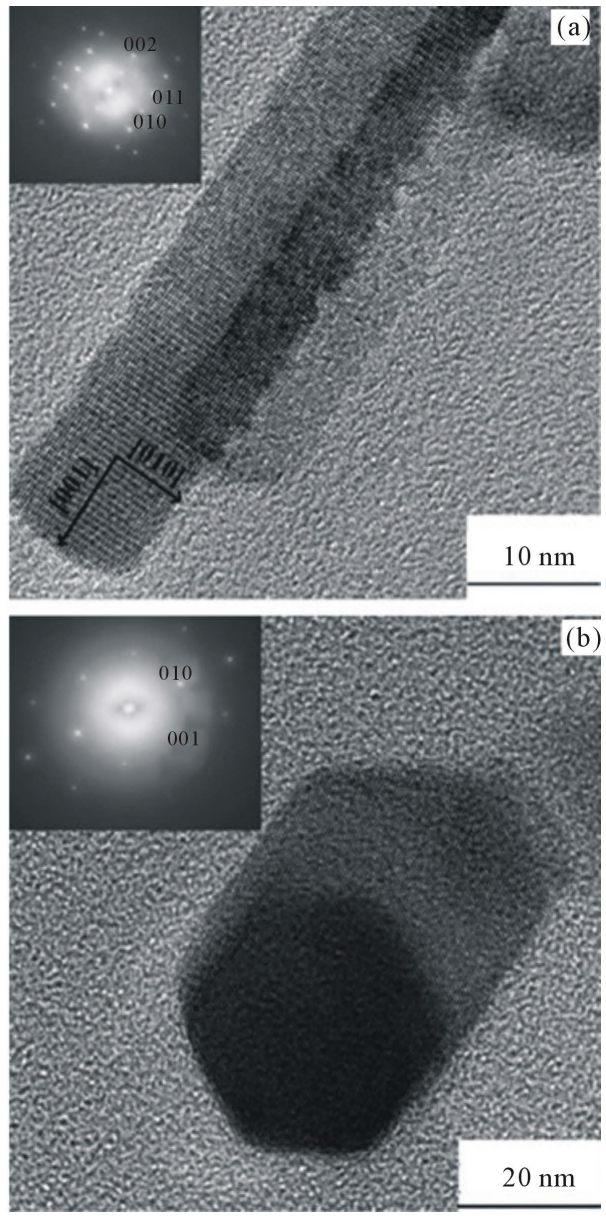

Figure 6. (a) HRTEM image of a ZnOnanorods lying on the TEM grid and the electron diffraction pattern in the inset showing lattice spacing and growth directions. (b) HRTEM image showing the basal plane of a hexagonal shaped wurtzite crystal standing inclined on the TEM grid support and its electron diffraction pattern (inset) confirming the growth of ZnOnanorod along the [001] direction.

the hexagonal shape is actually the basal plane of a hexagonally shaped Wurtzite structure; the longitudinal growth of the nanorod is along the [001] direction. It is also noted that in this case the zone axis for the diffraction pattern is also in the [001] direction.

Wang [1] reported various growth directions for $\mathrm{ZnO}$ nanorods. Other than the $\{001\}$ facet, the other facets along which the nanorods can grow are $\{010\}$ and $\{210\}$, due to their lower surface energies. The image of Figure 6(a) shows a nanorod that is lying on its surface. From the SAED pattern and the TEM image it can be concluded again that the transverse growth direction of the nanorods is along the [010] direction and hence the surface facet is in the [010] direction. The results correspond well to the previous work on ZnOnanorods [1,30], despite that our nanorods grow without any heterogeneous surface nucleation. Lattice spacing calculations showed $0.52 \mathrm{~nm}$ and $0.28 \mathrm{~nm}$, which correspond to the lattice spacing of the
(001) planes and the (010) planes, respectively, in the hexagonal crystal (see Figure 6(a)).

In the current work, from Figure 1, it can be seen that the precursor has been introduced from the $\mathrm{H}_{2}$ side of the flame. Kuniya et al. [31] studied the physicochemical properties of the DEZ in the presence and absence of hydrogen. Their studies showed that in the presence of hydrogen, DEZ decomposes above $200^{\circ} \mathrm{C}$ into ethyl and zinc. Due to the high temperature gradient in the CDF, the zinc formed tends to vaporize as it moves towards the flame. The atomic zinc from the precursor reacts with $\mathrm{H}_{2} \mathrm{O}$ in vapor state and may form either $\mathrm{Zn}(\mathrm{OH})_{2}$ or $\mathrm{ZnO}$ from dehydration of $\mathrm{Zn}(\mathrm{OH})_{2}$. Xing et al. [23] studied the chemical environments present on the either side of the CDF flame. Their studies showed that on the $\mathrm{H}_{2}$ side of the flame, there is an increase in concentration of the water vapor from the channel to the flame and decreasing concentration of $\mathrm{H}_{2}$. Therefore, the reactions forming aerosols could be

$$
\begin{gathered}
\mathrm{Zn}+2 \mathrm{H}_{2} \mathrm{O} \rightarrow \mathrm{Zn}(\mathrm{OH})_{2}+\mathrm{H}_{2} \\
\mathrm{Zn}(\mathrm{OH})_{2} \rightarrow \mathrm{ZnO}+\mathrm{H}_{2} \mathrm{O}
\end{gathered}
$$

These reactions, however, should occur in a much shorter time scale than the particle growth, and the particle growth would effectively involve only $\mathrm{ZnO}$.

The temperatures in such hydrogen flames would be in excess of $2000^{\circ} \mathrm{C}$ [32], which are higher than the melting point of $\mathrm{ZnO}\left(1970^{\circ} \mathrm{C}\right)$. It also has to be noted that the melting temperature of nanoparticles should be much lower than their theoretical melting temperatures [33]. Hence, in this case we can assume that the melting temperature of the $\mathrm{ZnO}$ formed is lesser than the flame temperature. If there is formation of $\mathrm{ZnO}$ aerosols on the fuel side, they can still melt as they flow to near the flame. If they pass through the flame they would certainly melts. Therefore, recrystallization would be the mechanism for the nanorod formation, rather than grow by molecular deposition. This growth mechanism is similar to the growth of doped $\mathrm{ZnO}$ studies done by Height et al. [8] using a FSP process.

As discussed earlier in the paper, $\mathrm{ZnO}$ exhibits a Wurtizite crystal structure and hence, when it recrystallizes it grows into a nanorod. The Wurtzite structure is anisotropic and studies done by Baxter et al. [34] have shown that anisotropic structure grows by repeated nucleation and growth of the epitaxial hexagonal pyramids on the [001] plane. It was also shown that, irrespective of the growth mechanisms for the other faces of the ZnOnanorod, the normal growth direction is always dominated by the repeated nucleation and growth on the [001] plane.

\subsection{Optical Studies of the ZnONanorods}

Raman scattering experiments were done on the synthe- 
sized $\mathrm{ZnO}$ aerosols at room temperature. According to group theory, near the Brillouin zone, there are eight sets of optical phonon modes at the center of the Brillouin zone ( $\Gamma$ point) showing Raman activity [35], where

$$
\Gamma=A_{1}+2 B_{1}+E_{1}+2 E_{2}
$$

The $B_{1}$ modes are known as silent modes since they are inactive in the Raman spectra [14,36,37]. The $A_{1}$ and $E_{1}$ modes are infrared active and split into two branches known as the transverse (TO) and longitudinal (LO) optical components. Figure 7(a) shows the Raman spectrum for the synthesized ZnOnanorods. A dominant, sharp and strong peak in the spectrum is seen at $437 \mathrm{~cm}^{-1}$, which corresponds to $E_{2}$ optical phonon mode of the $\mathrm{ZnO}$ crystal with a Wurtzite crystal structure. The additional peaks at $332 \mathrm{~cm}^{-1}$ and $389 \mathrm{~cm}^{-1}$ correspond to the $3 E_{2 \mathrm{H}}-E_{2 \mathrm{~L}}$ and $A_{1}$ (TO) phonon modes of the $\mathrm{ZnO}$ crystal. In a typical $\mathrm{ZnO}$ crystal, there is another distinct peak at approximately $559 \mathrm{~cm}^{-1}$ that corresponds to the $E_{1}$ (LO) phonon mode. This particular phonon mode appears when there are structural defects (e.g., oxygen vacancies, zinc interstitials and free carriers) and impurities. From Figure 7(a), it can be clearly seen that this peak is not distinct. A higher intensity and narrow spectral width of $E_{2}$ peak and a really weak $E_{1}(\mathrm{LO})$ peak indicate that the $\mathrm{ZnO}$ synthesized using this process is highly pure and without any oxygen vacancies.

Further optical study was conducted using photoluminescence (PL). Figure 7(b) shows the PL spectrum obtained for the synthesized $\mathrm{ZnO}$. The spectrum consists of a single peak at $387 \mathrm{~nm}$ in the UV region, which is the characteristic emission of $\mathrm{ZnO}$ due to the exciton combination [38]. It can also be seen that there are no predominant emissions from the visible region in the spectrum, which should correspond to intrinsic and extrinsic defects present in $\mathrm{ZnO}$ [38]. The Raman and PL results lead to our conclusion that there are no defects in $\mathrm{ZnO}$ nanorods synthesized in the CDF reactor and hence they are pure.

Optical absorbance studies have been done on the ZnOnanorods to determine its band gap. $\mathrm{ZnO}$ is a direct band gap semiconductor and for a direct band gap semiconductor, the absorption coefficient varies with the band gap as

$$
\alpha=\left[c\left(E-E_{0}\right)\right]^{1 / 2} .
$$

where $\alpha$ is the absorbance and $c$ is a constant [39]. Hence, plotting $\alpha^{2}$ against the energy in $\mathrm{eV}$ and extrapolating the line to the energy axis should give us the value of the band gap. Figure 8 shows the absorption spectrum. It can be seen that the band gap of the synthesized ZnOnanorods is $3.27 \mathrm{eV}$. This value is less than the theoretical value of $3.37 \mathrm{eV}$ as the technique employed may underestimate the original value of the band gap [39]. Litera-
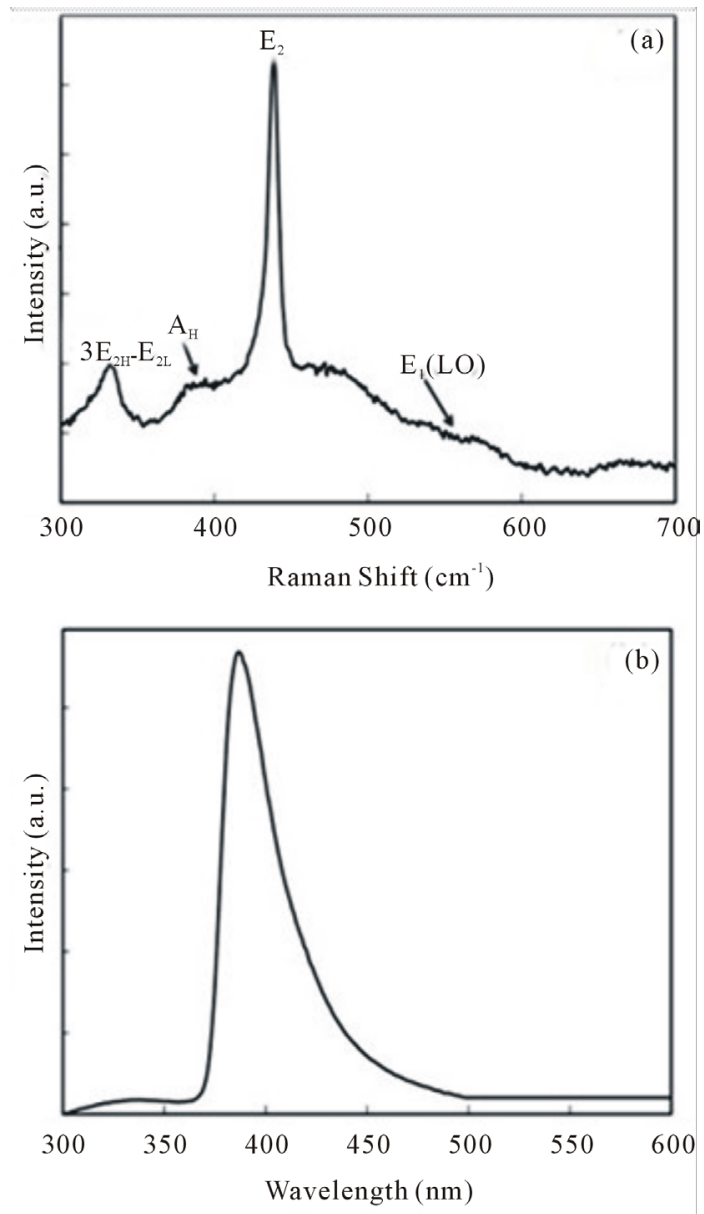

Figure 7. (a) Typical Raman spectra of synthesized ZnOnanorods using a He-Ne $(633 \mathrm{~nm})$ laser line as the excitation source. (b) Photoluminescence spectrum of $\mathrm{ZnO}$ powder.

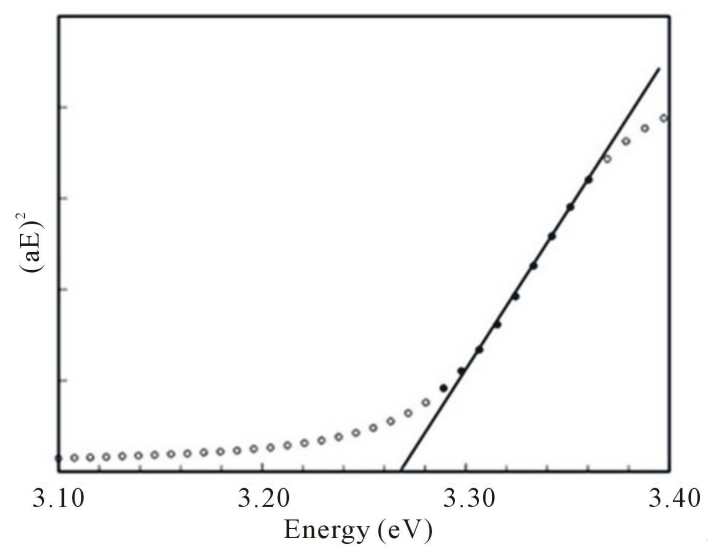

Figure 8. Dependence of absorption coefficient as a function of light energy for ZnOnanorods, from which the band gap is determined.

ture also states that measurement of band gap by this technique generally gives the value of the onset of the band gap rather than the original band gap. The square root dependence considered here is just valid for simple 
parabolic band transitions but does not account for the excitonic and other broadening effects [40].

TEM grids obtained from thermophoretic sampling were used to study the growth mechanism of the ZnOnanorods. A high-resolution TEM image shown in Figure 6(a) proves our previous conclusion.

\section{Conclusion}

Aerosols of ZnOnanorods have been synthesized by using a CDF reactor. No carbon contamination from hexane in the precursor was found from the XRD patterns, indicating that the nanorods were pure $\mathrm{ZnO}$. The nanorods were found to be highly crystalline with a Wurtzite structure. It was shown that the size of ZnOnanorods can be controlled by varying process parameters like gas flow rate, precursor flow rate and dilution of the combustion gases. TEM analysis and electron diffraction patterns showed that the nanorods formed in the [001] direction. Lattice spacing has been calculated to be 0.52 $\mathrm{nm}$ and $0.28 \mathrm{~nm}$, which corresponds to the (001) and (010) planes in the hexagonal crystal. Raman and PL spectroscopic studies have shown that the synthesized ZnOnanorods are highly pure without notable structural defects and impurities. Optical absorbance studies have shown that the band gap of synthesized ZnOnanorods is $3.27 \mathrm{eV}$. The work demonstrated that the CDF reactor could provide a convenient means for large-scale continuous manufacturing of aerosols of ZnOnanorods.

\section{Acknowledgements}

We would like to thank Army Research Office (AROW911NF-10-1-0476) and NSF (MRI 0922851) for their financial supports. We would also like to thank Dr. Eric Bohannan and Dr. Kai Song at the AMCL Laboratory at Missouri S\&T for their help in XRD and HRTEM analysis.

\section{REFERENCES}

[1] Z. L. Wang, "Zinc Oxide Nanostructures: Growth, Properties and Applications,” Journal of Physics Condensed Matter, Vol. 16, No. 25, 2004, pp. R829-R858. http://dx.doi.org/10.1088/0953-8984/16/25/R01

[2] S. Sakthivela, B. Neppolianb, M. V. Shankarb, B. Arabindoob, M. Palanichamy and V. Murugesan, "Solar Photocatalytic Degradation of Azo Dye: Comparison of Photocatalytic Efficiency of $\mathrm{ZnO}$ and $\mathrm{TiO}_{2}$," Solar Energy Materials and Solar Cells, Vol. 77, No. 1, 2003, pp. 6582. http://dx.doi.org/10.1016/S0927-0248(02)00255-6

[3] Y. Hao, M. Yang, W. Li, X. Qiao, L. Zhang and S. Cai, "A Photoelectrochemical Solar Cell Based on ZnO/Dye/ polypyrrole Film Electrode as Photoanode,” Solar Energy Materials and Solar Cells, Vol. 60, No. 4, 2000, pp. 349354. http://dx.doi.org/10.1016/S0927-0248(99)00053-7

[4] R. Jose, V. Thavasi and S. Ramakrishna, "Metal Oxides for Dye-Sensitized Solar Cells,” Journal of American
Ceramic Society, Vol. 92, No. 2, 2009, pp. 289-301. http://dx.doi.org/10.1016/j.ssc.2003.11.051

[5] X. C. Sun, H. Z. Zhang, J. Xu, Q. Zhao, R. M. Wang and D. P. Yu, "Shape Controllable Synthesis of ZnO Nanorod Arrays via Vapor Phase Growth,” Solid State Communications, Vol. 129, No. 12, 2004, pp. 803-807. http://dx.doi.org/10.1016/j.ssc.2003.11.051

[6] X. Y. Kong, Y. Ding, R. Yang and Z. L. Wang, "SingleCrystal Nanorings Formed by Epitaxial Self-Coiling of Polar Nanobelts,” Science, Vol. 303, No. 5662, 2004, pp. 1348-1351. http://dx.doi.org/10.1126/science.1092356

[7] N. Tamaekong, C. Liewhiran, A. Wisitsoraat and S. Phanichphant, "Flame Spray-Made Undoped Zinc Oxide Films for Gas Sensing Applications,” Sensor, Vol. 10, No. 8, 2010, pp. 7863-7873. http://dx.doi.org/10.3390/s100807863

[8] M. J. Height, L. Madler and S. E. Pratsinis, "Nanorods of ZnO Made by Flame Spray Pyrolysis," Chemistry of Materials, Vol. 18, No. 2, 2006, pp. 572-578.

http://dx.doi.org/10.1021/cm052163y

[9] A. B. Hartanto, X. Ning, Y. Nakata and T. Okada, "Growth Mechanism of ZnO Nanorods from Nanoparticles Formed in a Laser Ablation Plume,” Applied Physics A, Vol. 78, No. 3, 2004, pp. 299-301. http://dx.doi.org/10.1007/s00339-003-2286-2

[10] W. I. Park, D. H. Kim, S. W. Jung and G. C. Yi, "Metalorganic Vapor-Phase Epitaxial Growth of Vertically Well-Aligned ZnO Nanorods," Applied Physics Letters, Vol. 80, No. 22, 2002, pp. 4232-4234. http://dx.doi.org/10.1063/1.1482800

[11] J. J. Wu and S. C. Liu, "Low-Temperature Growth of Well-Aligned ZnO Nanorods by Chemical Vapor Deposition,” Advanced Materials, Vol. 14, 2002, pp. 215-218.

[12] F. Xu, C. D’Esposito, X. Liu, B. Kear and S. D. Tse, "Flame Synthesis of ZnON Anostrucutres: Morphology and Local Growth Conditions," Materials Research Society Symposium Proceedings, Vol. 1142, 2009, pp. JJ05JJ39.

[13] Y. C. Hong, J. H. Kim and H. S. Uhm, "ZnO Nanorods Synthesized by Self-Catalytic Method of Metal in Atmospheric Microwave Plasma Torch Flame,” Japanese Journal of Applied Physics, Vol. 45, No. 7, 2006, pp. 59405944. http://dx.doi.org/10.1143/JJAP.45.5940

[14] H. Peng, Y. Fangli, B. Liuyang, L. Jinlin and C. Yunfa, "Plasma Synthesis of Large Quantities of Zinc Oxide Nanorods,” Journal of Physical Chemistry C, Vol. 111, No. 1, 2007, pp. 194-200. http://dx.doi.org/10.1021/jp065390b

[15] M. K. Akhtar, S. E. Pratsinis and S. V. R. Mastrangelo, "Dopants in Vapor-Phase Synthesis of Titania Powders," Journal of American Ceramic Society, Vol. 75, No. 12, 1992, pp. 3408-3416. http://dx.doi.org/10.1111/j.1151-2916.1992.tb04442.x

[16] T. Tani, L. Madler and S. E. Pratsinis, "Homogeneous ZnO Nanoparticles by Flame Spray Pyrolysis," Journal of Nanoparticle Research, Vol. 4, No. 4, 2002, pp. 337-343. http://dx.doi.org/10.1023/A:1021153419671

[17] F. Xu, S. D. Tse, J. F. Al-Sharab and B. H. Kear, "Flame 
Synthesis of Aligned Tungsten Oxide Nanowires," Applied Physics Letters, Vol. 88, 2006, Article ID: 243115. http://dx.doi.org/10.1063/1.2213181

[18] P. M. Rao and X. Zheng, "Rapid Catalyst-Free Flame Synthesis of Dense, Aligned- $\mathrm{Fe}_{2} \mathrm{O}_{3}$ Nanoflake and Cuonanoneedle Arrays," Nano Letters, Vol. 9, No. 8, 2009, pp. 3001-3006. http://dx.doi.org/10.1021/nl901426t

[19] W. Merchan-Merchan, A. V. Saveliev and A. M. Taylor, "High Rate Flame Synthesis of Highly Crystalline Iron Oxide Nanorods," Nanotechnology, Vol. 19, 2008, Article ID: 125605.

http://dx.doi.org/10.1088/0957-4484/19/12/125605

[20] W. Merchan-Merchan, A. V. Saveliev and V. Nguyen, "Opposed Flow Oxy-Flame Synthesis of Carbon and Oxide Nanostrucutres on Molybdenum Probes," Proceedings of the Combustion Institute, Vol. 32, No. 2, 2009, pp. 18791886. http://dx.doi.org/10.1016/j.proci.2008.07.025

[21] S. L. Chung and J. L. Katz, "The Counterflow Diffusion Flame Burner: A New Tool for the Study of the Nucleation of Refractory Compounds," Combustion and Flame, Vol. 61, No. 3, 1985, pp. 271-279. http://dx.doi.org/10.1016/0010-2180(85)90108-7

[22] Y. Xing, U. O. Koylu and D. E. Rosner, "Synthesis and Restructuring of Inorganic Nanoparticles in Counterflow diffusion Flames," Combustion and Flame, Vol. 107, No. 1996, pp. 85-102. http://dx.doi.org/10.1016/0010-2180(96)00005-3

[23] Y. Xing, T. P. Kole and J. L. Katz, "Shape Controlled Synthesis of Iron Oxide Nanoparticles," Journal of Materials Science Letters, Vol. 22, No. 11, 2003, pp. 787-790. http://dx.doi.org/10.1023/A:1023923104337

[24] G. C. Yi, C. Wang and W. I. Park, "ZnO Nanorods: Synthesis, Characterization and Applications," Semiconductor Science and Technology, Vol. 20, No. 4, 2005, pp. S22-S34. http://dx.doi.org/10.1088/0268-1242/20/4/003

[25] M. R. Zachariah, D. Chin, H. G. Semerjian and J. L. Katz, "Silica Particle Synthesis in a Counterflow Diffusion Flame Reactor," Combustion and Flame, Vol. 78, No. 3-4, 1989, pp. 287-298. http://dx.doi.org/10.1016/0010-2180(89)90018-7

[26] I. S. Altman, I. E. Agranovski and M. Choi, "Nanoparticle Generation: The Concept of a Stagnation Size Region for Condensation Growth,” Physical Review E, Vol. 70, 2004, Article ID: 062603. http://dx.doi.org/10.1103/PhysRevE.70.062603

[27] T. P. Pandya and F. J. Weinberg, "The Structure of Flat Counterflow Diffusion Flames," Proceedings of the Royal Society London, Series A: Mathematical and Physical Sciences, Vol. 279, No. 1379, 1964, pp. 544-561. http://dx.doi.org/10.1098/rspa.1964.0124

[28] D. C. Kim, B. H. Kong and H. K. Cho, "Synthesis and Growth Mechanism of Catalyst Free ZnO Nanorods with Enhanced Aspect Ratio by High Flow Additional Carrier Gas at Low Temperature,” Journal of Physics D: Applied Physics, Vol. 42, 2009, Article ID: 065406. http://dx.doi.org/10.1088/0022-3727/42/6/065406

[29] L. Vayssieres, K. Keis, A. Hagfeldt and S. E. Lindquist, "Three-Dimensional Array of Highly Oriented Crystalline ZnO Microtubes," Chemistry of Materials, Vol. 13, No. 12, 2001, pp. 4395-4398. http://dx.doi.org/10.1021/cm011160s

[30] C. Ye, X. Fang, Y. Hao, X. Teng and L. Zhang, “Zinc Oxide Nanostrucutres: Morphology Derivation and Evolution,” Journal of Physical Chemistry B, Vol. 109, No. 42, 2005, pp. 19758-19765. http://dx.doi.org/10.1021/jp0509358

[31] Y. Kuniya, Y. Deguchi and M. Ichida, "Physicochemical Properties of Dimethylzinc, Dimethylcadmium and Diethylzinc," Applied Organometallic Chemistry, Vol. 5, No. 4, 1991, pp. 337-347. http://dx.doi.org/10.1002/aoc.590050419

[32] H. E. Ruiz, "Synthesis of Iron Oxide Nanoparticles in a Counterflow Diffusion Flame Reactor," M.S. Thesis, Missouri University of Science and Technology, 2008.

[33] Ph. Buffat and J-P. Borel, "Size Effect on Melting Temperature of Gold Particles,” Physical Review A, Vol. 13, No. 6, 1976, pp. 2287-2298. http://dx.doi.org/10.1103/PhysRevA.13.2287

[34] J. B. Baxter, F. Wu and E. S. Aydil, "Growth Mechanism and Characterization of Zinc Oxide Hexagonal Columns," Applied Physics Letters, Vol. 83, No. 18, 2003, pp. 37973799. http://dx.doi.org/10.1063/1.1624467

[35] J. M. Calleja and M. Cardona, "Resonant Raman Scattering in ZnO,” Physical Review B, Vol. 16, No. 8, 1977, pp. 3753-3761. http://dx.doi.org/10.1103/PhysRevB.16.3753

[36] A. Umar, S. H. Kim, Y. S. Lee, K. S. Nahm and Y. B. Hahn, "Catalyst-Free Large-Quantity Synthesis of ZnONanorods by Vapor-Solid Growth Mechanism: Structural and Optical Properties,” Journal of Crystal Growth, Vol. 282, No. 1-2, 2005, pp. 131-136. http://dx.doi.org/10.1016/j.jcrysgro.2005.04.095

[37] R. S. Zeferino, M. B. Flores and U. Pal, "Photoluminescence and Raman Scattering in Ag-Doped ZnONanoparticles,” Journal of Applied Physics, Vol. 109, 2011, Article ID: 014308. http://dx.doi.org/10.1063/1.3530631

[38] H. Zeng, G. Duan, Y. Li, S. Yang, X. Xu and W. Cai, "Blue Luminescence of ZnO Nanoparticles Based on Non-Equilibrium Processes: Defect Origins and Emission Controls,” Advanced Functional Materials, Vol. 20, No. 4, 2010, pp. 561-572. http://dx.doi.org/10.1002/adfm.200901884

[39] Y. Wang, I. Ramos and J. J. Santiago-Aviles, “Optical Bandgap and Photoconductance of Electrospun Tin Oxide Nanofibers,” Journal of Applied Physics, Vol. 102, 2007, Article ID: 093517. http://dx.doi.org/10.1063/1.2800261

[40] C. F. Klingshirn, B. K. Meyer, A. Waag, A. Hoffman and J. Geurts, "Zinc Oxide: From Fundamental Properties towards Novel Applications,” Springer, Berlin, 2010. http://dx.doi.org/10.1007/978-3-642-10577-7 